\title{
Imaging of Pelvic Lymph Nodes
}

\author{
Yun Mao $\cdot$ Sandeep Hedgire $\cdot$ Duangkamon Prapruttam $•$ \\ Mukesh Harisinghani
}

Published online: 16 September 2014

(C) Springer Science+Business Media New York 2014

\begin{abstract}
Imaging evaluation to determine the status of pelvic lymph nodes has yet to attain benchmark status clinically. On one hand, pelvic lymphatic drainage is complex and varies depending on the types and locations of primary tumors. On the other hand, current imaging techniques still have the potential to improve the detection of micrometastatic lesions and differentiation between hyperplastic and malignant nodes. This article addresses the strengths and weaknesses of imaging techniques as well as specific lymphatic metastatic routes that could increase the diagnostic confidence concerning pelvic lymph nodes.
\end{abstract}

Keywords Lymph node - Pelvic - Cancer - Metastasis · Imaging $\cdot$ Computed tomography $\cdot$ Magnetic resonance imaging

\section{Introduction}

Pelvic lymph node (LN) metastasis is an important prognostic factor in all male and female malignant urogenital neoplasms. Prior to surgery, familiarity with the lymphatic drainage pathways and accurate mapping of positive LNs may reduce the postoperative recurrence and prolong survival, as well as decrease the morbidity and mortality caused by the gold standard, pelvic LN dissection. In this article, we describe the primary lymphatic drainage pathway for common pelvic urogenital malignancies and summarize the common imaging characteristics of pelvic metastatic LNs as well as some emerging imaging technologies in this field.

\section{Pelvic Lymphatic Drainage Pathways}

\section{General Pelvic Lymphatic Spread}

The lymphatic drainage patterns of urogenital malignancies are complex in the pelvis. The metastases usually involve specific sentinel lymph nodes (SLNs) along the supply or drainage vessels of the organs with primary tumors. This is followed by further spread to the next LN station. Skip metastases of $\mathrm{LN}$ seldom occur in urogenital tumors. There are four main pathways of pelvic LNs (Fig. 1): (1) the anterior route, which drains lymph from the anterior wall of the bladder along the umbilical artery to the internal iliac (hypogastric) nodes; (2) the lateral route, which drains lymph from the pelvic organs to the medial chain of the external iliac nodal group (obturator LNs); (3) the hypogastric route, which drains along the visceral branches of the hypogastric vessels to the junctional nodes located between the internal and external iliac vessels; (4) the 
Fig. 1 Anatomical location of pelvic lymph nodes. a Anterior view. b Lateral view
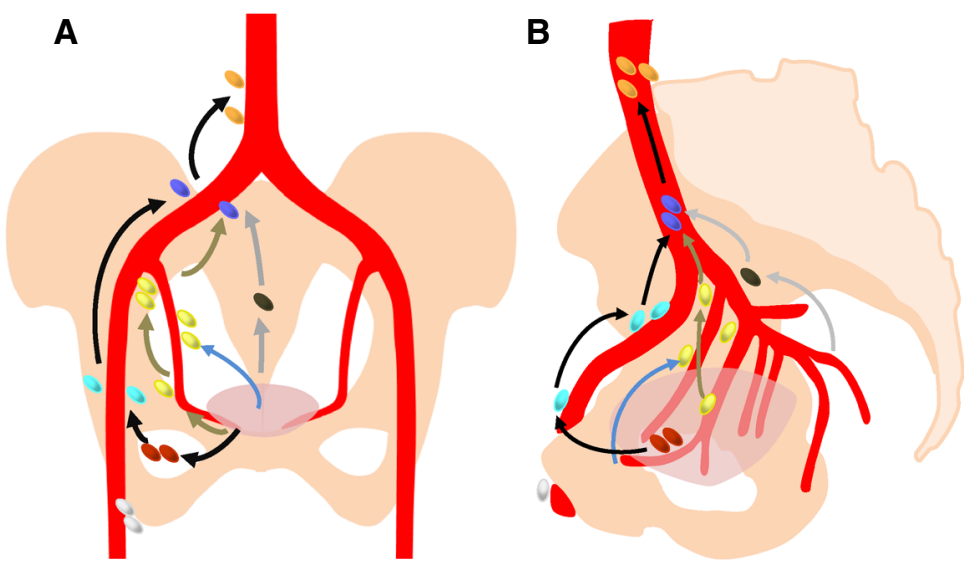

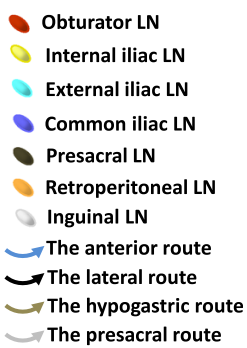

presacral route, which includes the LNs anterior to the sacrum and coccyx [1••]. Among them, the lateral route is the most common pathway, and the anterior route is the rarest.

\section{Prostate Cancer}

The survival rate of patients with prostate cancer correlates with LN metastasis, with a 5-year tumor-free survival rate of $85 \%$ for pN0 disease decreasing to approximately $50 \%$ for $\mathrm{pN} 1$ disease [2]. The lymphatic drainage of prostate cancer (Fig. 2a) mainly spreads along the lateral route to the obturator LNs, the most common SLNs (up to $60 \%$ ), from which the metastases spread to the middle and lateral external iliac LNs. Besides, the junctional nodes belonging to the hypogastric lymph group are also commonly involved because of the hypogastric route. Metastatic nodes in the presacral region are relatively rare [3]. Mattei and colleagues provided a detailed SLN map of the prostate using a multimodality technique [including SPECT/CT, SPECT/MRI, and ultrasound-guided intraprostatic injection of technetium (Tc-99m) nanocolloid]. They observed the SLN distribution as follows: external iliac and obturator fossa $(37.9 \%)$, internal iliac $(22.6 \%)$, presacral and pararectal $(8.2 \%)$, common iliac $(15.8 \%)$, para-aortic/paracaval $(12.0 \%)$, and inguinal $(0.6 \%)$ [4•]. The study by Weckermann et al. obtained similar results. They found $86 \%$ positive pelvic nodes distributed in the internal iliac (35\%), external iliac (26\%), and obturator $(25 \%)$ regions followed by the presacral (9\%), common iliac (3\%), and aortic bifurcation ( $1 \%$ ) regions. These data evidenced that quite a few metastatic pelvic lymph nodes are located outside the template area (external iliac, obturator fossa, and internal iliac regions) of standard pelvic lymphadenectomy. The missed rate of standard dissection reached up to $63 \%$, mainly contributed by presacral, common iliac, and retroperitoneal LNs [5]. Most of the prostate studies supported that there was no skip metastasis to the second level region (the common iliac and retroperitoneal LNs) if the first level region (the obturator, external and internal iliac, and presacral LNs) was negative, although up to $15 \%$ of positive nodes were detected in the aorta and vena cava regions $[6,7]$.

\section{Cervical Cancer}

The stages of cervical cancer are positively correlated with the LN status. From stage IA, IB, IIA, and IIB, the metastatic rates of lymph nodes are $0-8,0-17,12-27$, and 25-39\%, respectively [8]. However, LN metastasis to the pelvic and para-aortic regions cannot alter the FIGO staging, only influencing the prognosis [9]. In locally advanced cervical cancer, the 5-year survival rate decreases from $57 \%$ in patients without LN involvement to $34 \%$ in those with positive pelvic nodes and $12 \%$ in those with positive para-aortic nodes [10]. Lymphatic metastases in cervical cancer depend on three main routes (Fig. 2b): the lateral route is the main one, which spreads through the lateral parametrium and drains to the external iliac, internal iliac, and gluteal LNs; the anterior route is next, which drains along the vesicouterine ligament to internal iliac LNs; the posterior route, which drains along the sacrouterine ligament and the ureter to the presacral, common iliac, and para-aortic LNs, is rarely observed [11]. As a midline structure, the lymphatic drainage of the cervix can spread to the bilateral pelvic regions. The SLNs are distributed in seven retroperitoneal groups (paracaval, precaval, retrocaval, intercavoaortic, preaortic, paraaortic, retroaortic) and eight pelvic regions (deep and superficial common iliac, external iliac, deep and superficial obturator, internal iliac, presacral, parametric) [12•]. In early cervical cancer, the obturator nodes are the most common SLNs, which combined with external iliac nodes could comprise over $75 \%$ of all SLNs [13]. Rob et al. also identified the positive SLN distribution to be $45.5 \%$ supra-obturator nodes and $38.6 \%$ external iliac nodes, followed by $6.8 \%$ 

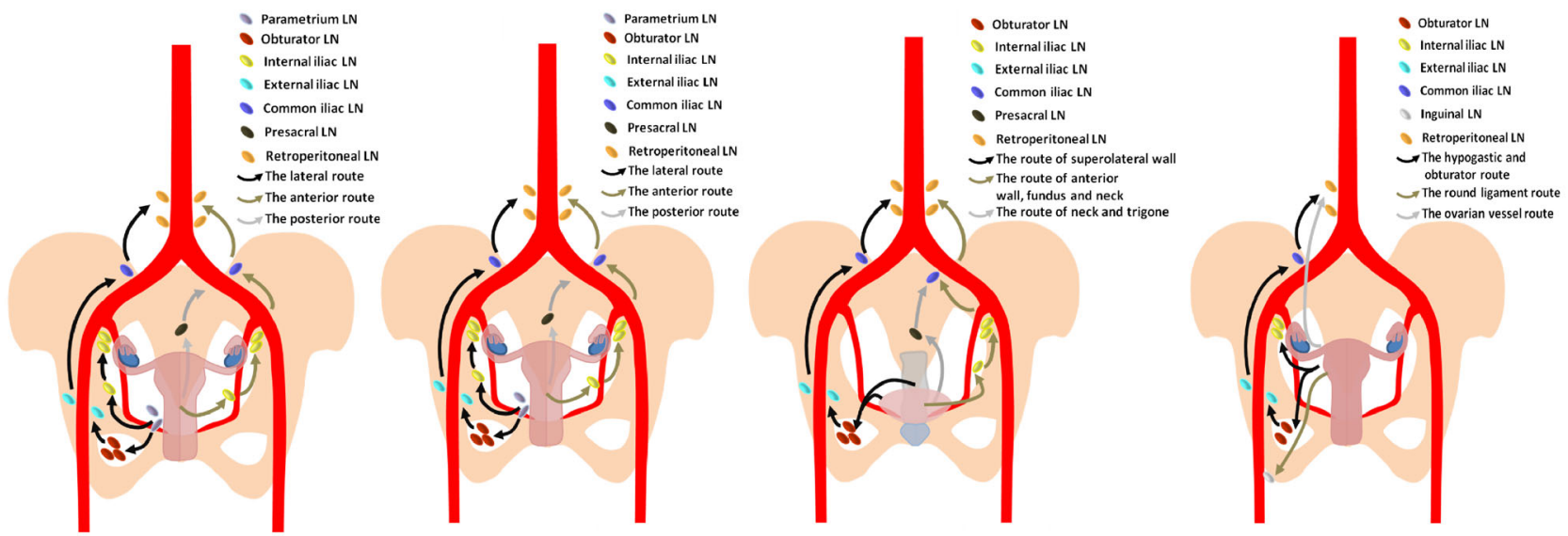

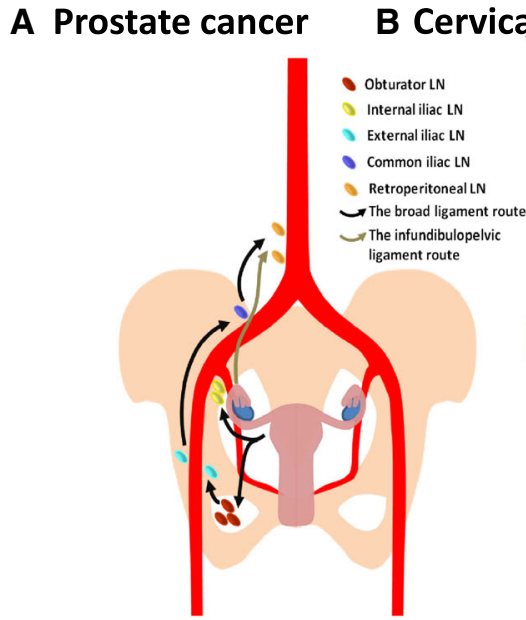

E Ovarian cancer

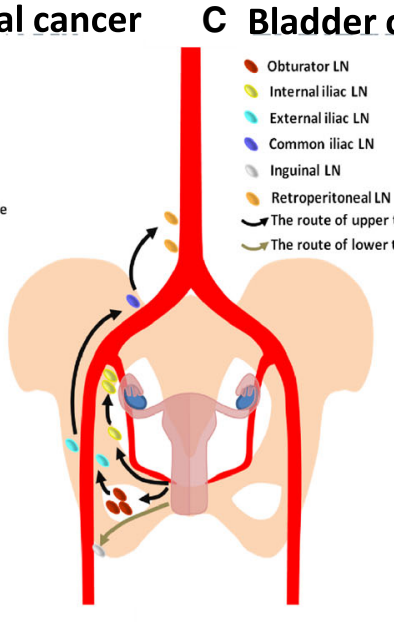

F Vaginal cancer

\section{ncer}

Internal iliac LN

SRALN

- IMA root LN

$\rightarrow$ The superior route

The lateral route

IMA: interior mesenteric arter

SRA: superior rectal artery

MRA: middle rectal artery

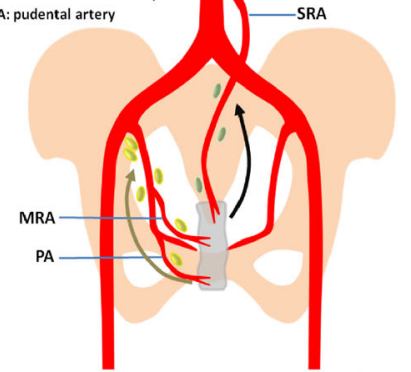

G Rectal cancer

Fig. 2 The illustrations of specific lymphatic drainage pathways of pelvic tumors

bifurcation and common iliac nodes, $4.5 \%$ presacral nodes, and $4.5 \%$ the medial part of the lateral parametrium [14]. An extremely close correlation between parametrial involvement and positive pelvic nodes was demonstrated by Benedetti-Panici et al. [15]. Just like in prostate cancer, common iliac, para-aortic, and inguinafemoral LNs are commonly seen as secondary metastatic sites in cervical cancer, while skip metastasis to para-aortic LNs is only reported in $<1 \%$ cases [16].

\section{Bladder Cancer}

The survival time of bladder cancer is negatively correlated with the number and size of the involved nodes, and it declines with capsular penetration of the nodes [17, 18]. The classic lymphatic channels of the bladder first spread to the perivesical LNs and then reach the other primary nodal basins in the iliac and presacral regions [19]. The obturator and internal iliac nodes are the most common
SLNs [20]. The lymphatic landing site varies by the bladder tumor locations (Fig. 2c). Lymphatic metastasis from tumors in the superolateral wall commonly spreads to external iliac LNs, whereas those from the anterior wall, fundus, and neck tend to involve internal iliac LNs. Besides, a few sacral nodes can be directly involved by tumors in the neck and trigone [21••]. All three LN groups can further spread upward to the bilateral common iliac and para-aortic regions, especially in patients with higher $\mathrm{T}$ stage tumors [22]. In a multicenter study, Leissner et al. identified the metastatic $\mathrm{LN}$ distribution in bladder cancer as follows: 14.1 and $6.9 \%$ right and left obturator spaces, 11.0 and $8.1 \%$ right and left deep obturator spaces, 6.7 and $7.0 \%$ right and left lateral to external iliac artery, $6.3 \%$ both the right and left lateral to common iliac artery, $6.0 \%$ presacral, and $12.9 \%$ retroperitoneal [23]. Abol-Enein et al. also supported the obturator LNs as the most common positive SLNs of bladder tumors. They also pointed out that skip metastasis might not exist in bladder cancer since 
isolated extrapelvic nodal disease was not detected. Bilateral nodal involvement is common and occurred in approximately $39 \%$ of bladder cancers, even if the primary lesion was limited to the unilateral wall of the bladder [20]. Based on this, both Abol-Enein and Leissner emphasized the need to promote bilateral lymphadenectomies.

\section{Endometrial Cancer}

The prognosis of endometrial cancer is strongly impacted by pelvic LN metastases [24], with a 5-year recurrence-free survival of $90 \%$ in patients without $\mathrm{LN}$ involvement versus $75 \%$ in those with positive pelvic $\mathrm{LNs}$ and $38 \%$ in those with positive para-aortic LNs [25]. Three main paths of lymphatic spread of the uterine corpus have been described, as shown in Fig. 2d: the most common route drains through the hypogastic or obturator regions to the common iliac LNs; next, spreading along the round ligament to the inguinal LNs takes place; the last directly involves the para-aortic LNs through the ovarian vessels. The external iliac and obturator nodes are most commonly affected in endometrial cancer [26, 27•]. When the tumor is confined to the corpus, isolated positive LNs spread to the external iliac and obturator regions more frequently, while if the cervical area is invaded, the external and common iliac regions are more common [27•]. Although direct lymphatic drainage to the para-aortic region is more commonly detected in endometrial cancer confined to the corpus than in tumors invading the cervix [27•,28], most of involved para-aortic nodes are associated with the presence of pelvic nodal metastasis, especially positive obturator nodes $[27 \bullet]$.

\section{Ovarian Cancer}

The incidence of LN metastasis of ovarian cancer largely depends on the histological subtypes and grades of primary tumors. In a systematic review, Kleppe et al. concluded LN metastasis was absent in clinical stage I-II sex cord stromal tumors, but present in as much as 11 and $18.1 \%$, respectively, in stage I-II malignant germ cell tumors and dysgerminoma of the ovary [29]. Moreover, from grade 1 to 3, the incidence rate of LN metastasis increased from 4.0 to $20.0 \%$ [30]. The lymphatic spread of ovarian cancer may take two main pathways (Fig. 2e): one follows the broad ligament to the internal iliac, external iliac, and obturator LNs; another one drains along the infundibulopelvic ligament to the aortic LNs [31•]. Therefore, both pelvic and para-aortic LNs could be primary metastatic SLNs of ovarian cancers. There is a third uncertain route, which spreads through the bilateral round ligament of the uterus to the external iliac and deep inguinal LNs [32]. The involved LNs are most frequently detected in the para- aortic region ( $83 \%$ ), followed by the external iliac region $(59 \%)$ and obturator region (53\%) [33]. Both unilateral and bilateral ovarian tumors can involve bilateral pelvic LNs. Cass et al. observed isolated ipsilateral, isolated contralateral, and bilateral node metastases comprised $50 \%(5 / 10), 30 \%(3 / 10)$, and $20 \%(2 / 10)$, respectively [34].

\section{Vaginal Cancer}

In traditional opinions, the lymphatic drainage of vaginal cancer depends on the locations of the primary tumors. Similarly to cervical cancer, nodal metastasis of upper tumors usually extends to deep pelvic (including internal and external iliac and obturator nodes) and para-aortic LNs, while lower tumors are more likely to involve the inguinofemoral triangle than vulvar cancer (Fig. 2f). However, recent studies demonstrated $\mathrm{LN}$ metastases did not follow the traditional routes so exactly. Frumovitz et al. noted $55.6 \%(5 / 9)$ of patients with vaginal cancer present positive nodes in unexpected regions. Three patients with lower tumors had an SLN in the pelvis, and two patients with upper tumors had an SLN in the inguinal triangle [35].

\section{Rectal Cancer}

As intraoperative assessment of the $\mathrm{LN}$ status by the surgeon is not reliable [36] and SLN biopsy is not as valuable as its application in other tumors [37], understanding the lymphatic drainage patterns of rectal cancer is essential to correctly estimate pelvic node status and decrease the postoperative recurrence rate. The lymphatic extension of rectal cancer is mainly based on two pathways (Fig. 2g): one is the superior route, spreading along the superior rectal artery to the root of the inferior mesenteric artery; another is the lateral route, spreading along the middle rectal and pudendal arteries to the root of the internal iliac artery [38-40]. There is a correlation between the locations of tumors [upper, above the peritoneal reflection (PR); lower, below the PR; middle, at the level of the PR] and the patterns of LN metastasis. Compared with tumors above the PR, tumors below the PR have more nodal metastases and a greater tendency to spread to the bilateral pelvic nodes through the lateral pathway [41•]. Besides, the pathohistological characteristcs of primary tumors, including the tumor size, depth of bowel wall invasion, number of positive mesorectal nodes, differention type, and lymphatic and venous invasion, also impact pelvic nodal metastasis [38, 39, 41]. The most common positive pelvic LNs in lower recal cancer are in the middle rectal root region $(19 \%)$ followed by the internal iliac region $(9 \%)$, obturator region $(9 \%)$, external iliac region $(7 \%)$, and common iliac region $(4 \%)[38,39]$. 


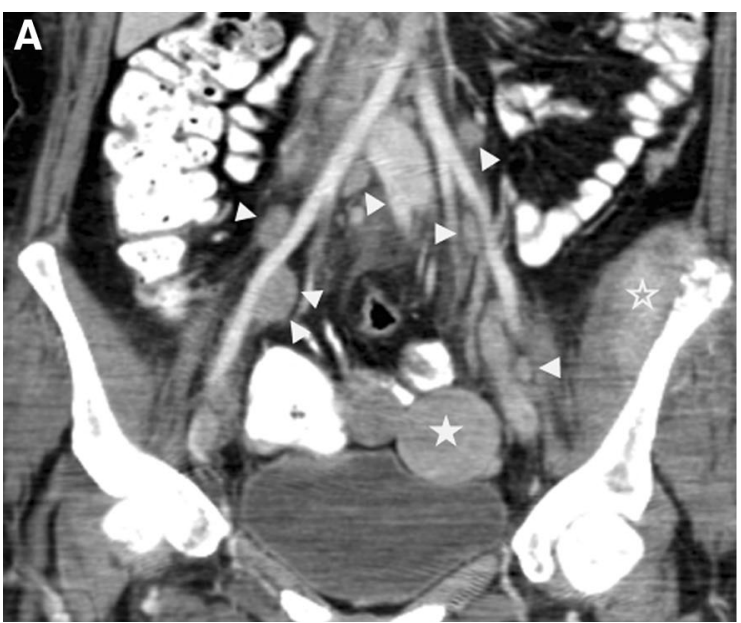

Fig. 3 Coronal reconstructed CT images have the advantage in discriminating pelvic lymph nodes from adjacent vessels. a Multiple metastatic lymph nodes (arrowheads) spreading along the common and external iliac arteries were clearly demonstrated on the coronal enhanced CT image.

\section{Imaging Methods}

Common imaging modalities for assessment of pelvic LNs are mainly classified into three divisions: first, conventional cross-sectional imaging, including computed tomography (CT) and magnetic resonance imaging (MRI); second, functional imaging, including functional MRI (fMRI), lymphotropic MR contrast, position emission tomography/ CT (MRI) [PET/CT (MRI)], and single photon emission computed tomography/CT (MRI) lymphoscintigraphy (SPECT/CT (MRI) LSG); third, interstitial CT (MRI) lymphography (ICTLG or IMRILG). In addition, there are some emerging modalities, such as photoacoustic technology and nanotechnology, that also display potential in the detection of pelvic nodal LN metastases.

\section{Conventional Cross-Sectional Imaging}

\section{$C T$}

$\mathrm{CT}$ is one of the most widely used imaging modalities in the evaluation of pelvic LN status. Various CT appearances have been adopted as diagnostic standards, alone or in combination, for assuring accuracy in differentiating between benign and malignant LNs. These LN features include the size, shape, border, margin, extracapsular invasion, intranodal texture, patterns, and degree of enhancement; of these, size is still the preferred one despite the low sensitivity reported by many studies $[42,43]$. The size threshold of pelvic LNs ranges from 0.5 to $2 \mathrm{~cm} \mathrm{[44,}$ 45]. A short axis diameter above $1 \mathrm{~cm}$ with an oval shape or $0.8 \mathrm{~cm}$ with a round shape is generally accepted as the criterion for metastasis [43, 46]. With this criterion, the specificity for detecting positive pelvic $\mathrm{LN}$ on $\mathrm{CT}$ reached

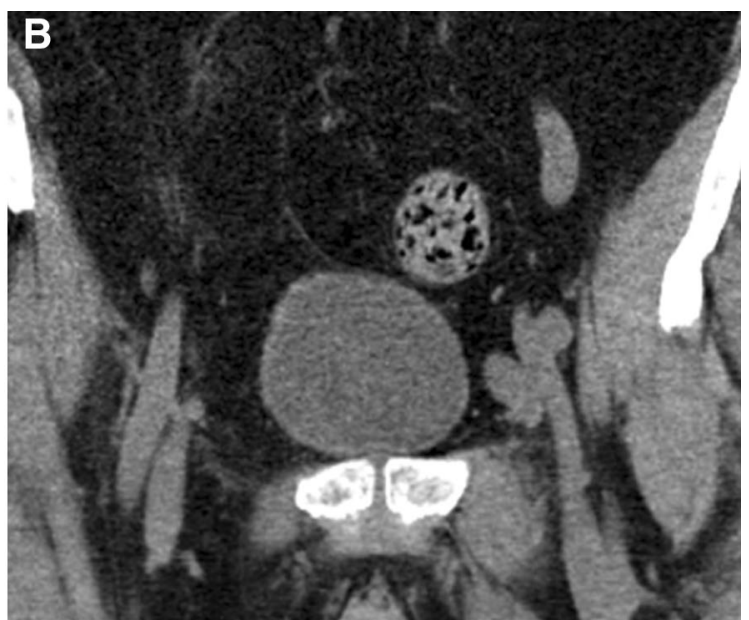

Additionally, a metastatic mass (hollow asterisk) with destruction of the iliac bone and pelvic mass (asterisk) above the bladder were noted. b Coronal precontrast CT image displayed an enlarged external iliac lymph node, which was confirmed as reactive hyperplasia

$97 \%$, but the sensitivity was only $34 \%$ [47]. The low sensitivity is due to false-positive cases caused by hypoplasia and enlargement of LNs associated with local inflammation as well as false-negative cases due to micrometastases (smaller than $2 \mathrm{~mm}$ ) hiding in nodes of normal size (short diameter less than $10 \mathrm{~mm}$ ) [48]. This phenomenon was proved by studies on prostate and cervical cancers. It is more common in the pelvic than retroperitoneal region [49-51]. Necrosis and calcification within the nodes are considered specific CT signs of metastatic nodes, especially with the same manifestations in primary tumors. Necrotic LNs frequently occur in cervical cancer and bladder cancer [21, 52], while calcification can be noted in ovarian cancers [53]. However, these features should be cautiously discriminated from other benign statuses, such as necrotizing lymphadenitis and tuberculosis. Moreover, the sensitivity of necrosis $(27 \%)$ is even lower than size despite the high PPV (100\%) [52]. Threedimensional (3D) reconstructed images of multidetector $\mathrm{CT}$ are useful in differentiating LNs from accompanying vessels and detecting small nodes [54]; see Fig. 3.

\section{MRI}

In spite of the excellent soft tissue resolution, conventional MRI cannot provide higher diagnostic value than CT does since its main diagnostic standards still rely on the structural features of LNs [43]. The sensitivity, specificity, accuracy, PPV, and NPV of conventional MRI in the assessment of pelvic LNs for all tumor types are 58-95.8, 15.4-78.5, 41.9-97.8, 15.4-85.7, and 47.4-97.8\%, respectively [5558]. The signal differences between positive and negative nodes on T1- and T2-weighted images are not significant [59]. Although extracapsular nodal spread and necrosis were 


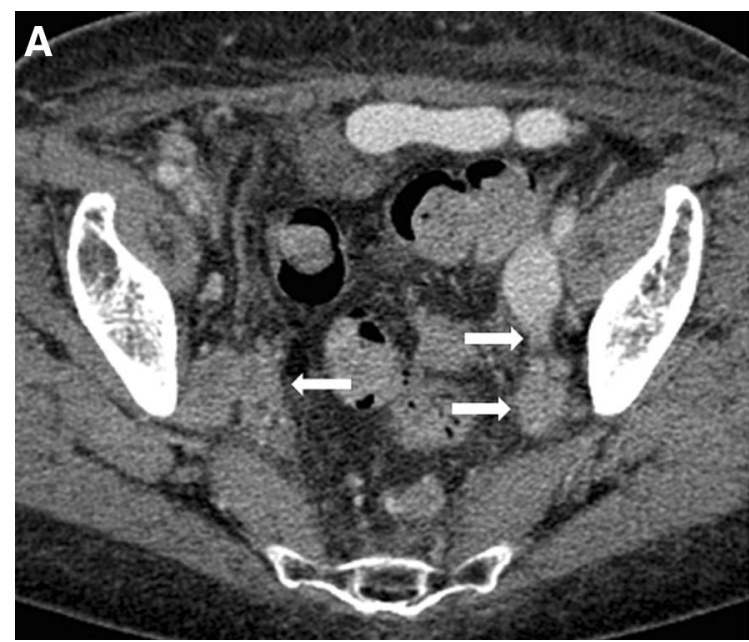

Fig. 4 A 78-year-old female patient with anorectal cancer. a Axial enhanced CT showed bilateral enhanced obturator and internal iliac lymph nodes (arrows) with slightly hetrogeneous enhancement and

more easily demonstrated on MRI than on CT and high specificities (94 and $100 \%$ respectively) were reported in differentiating pelvic hyperplasia and malignant nodes, their sensitivities were extremely low (21 and $15 \%$ ) [60]; see Fig. 4. Even in gadolinium-enhanced MRI, a simple comparison of signal alternations before and after enhancement is not an obvious help in identifying the LN status [43, 61]. Fischbein et al. noted the enhancement kinetics of malignant and benign LNs were different. Malignant LNs demonstrated a significantly longer peak time, lower peak enhancement, lower maximum slope, and slower washout slope on the time/signal curves, which might indicate tumors have lower transfer of contrast agent to tissue and a decreased volume of extravascular and extracellular space compared to normal or reactive nodes. However, the results of the studies on enhancement kinetics are difficult to reproduce [62].

Functional Imaging

\section{$D W I$}

The imaging basis of DWI is to detect the diversity of microscopic water molecular diffusion movement in different tissues and consequently reflect their biophysical characteristics and changes [63]. This technology has been widely used in the evaluation of lymphopathy and shows a significantly higher sensitivity in detecting lymph nodes compared to conventional CT and MRI [58, 64], even to PET/CT [65]. The sensitivity, specificity, and accuracy of DWI are 57-86, 79-85.3, and 70-85.6\% for prostate cancer [64, 66], 83.3-87, $51.2-80$, and $57.0-90.2 \%$ for uterine cancer [67••, 68], and $80,76.9$, and $78.3 \%$ for colorectal cancers [65], respectively. As the index of quantitative assessment of DWI, the apparent diffusion coefficient (ADC) value is commonly demonstrated

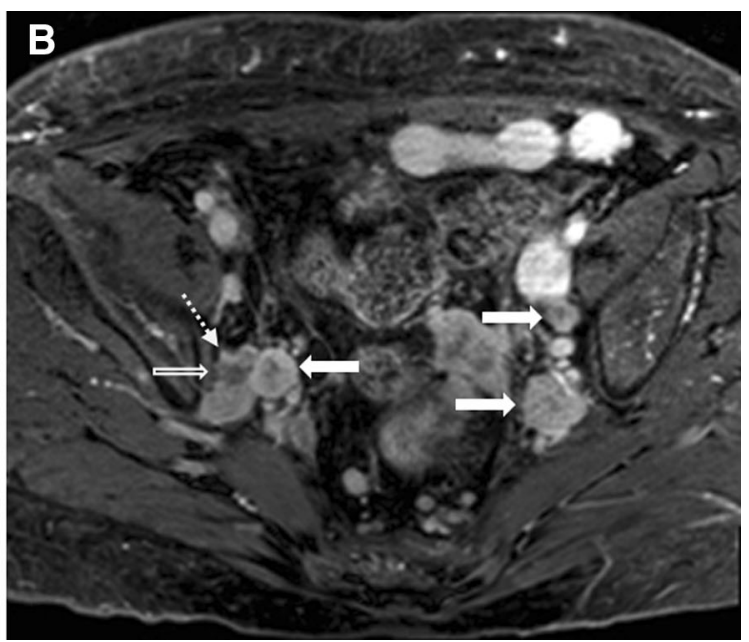

ill-defined margins. b T1-weighted MR image clearly displayed necrosis (hollow arrow) within these metastatic nodes as well as extracapsular extension (dashed arrow)

at a significantly lower level in malignant LNs than in benign LNs [69]; see Fig. 5. The possible cause is that the water molecular movement is less restricted in benign nodes than in malignant ones because of their higher cellular density and less extracellular space [70]. In a study of cervical cancer, Lin et al. identified the relative ADC value was significantly lower in metastatic nodes than in non-metastatic nodes, 0.06 versus $0.21 \times 10^{-3} \mathrm{~mm}^{2} / \mathrm{s}, p<0.001$ [58]. However, two inherent weaknesses limit the use of this modality in lymphopathy. First, its diagnostic accuracy is not very reliable in normal size nodes with micrometastasis because of image distortion and relatively poor spatial resolution [71]. Innovations of DWIrelated technologies, such as parallel imaging, periodically rotated overlapping parallel lines, and short time inversion recovery DWI, may improve the detection sensitivity somehow $[72,73]$. Second, a limitation of DWI is that there is a great deal of overlap of the ADC values between benign and malignant nodes. Hyperplasia and other benign pathological alternations (such as abscesses) also can restrict water diffusion within nodes, thus leading to similarly low ADC values as those of malignant nodes. Roy et al. pointed out that there was no significant difference in ADC values among the involved lymph nodes, control iliac nodes, and control inguinal nodes, with the mean $\mathrm{ADC}$ value \pm standard deviation $\left(\times 10^{-3}\right.$ $\mathrm{mm}^{2} / \mathrm{s}$ ) being $924 \pm 217,968 \pm 182$, and $1,036 \pm 181$, respectively [74].

\section{USPIO}

Lymphotropic MR contrast is another hopeful innovation in MR lymphography, with the most commonly used being USPIO (ferumoxtran-10). USPIO is a cell-specific contrast medium, which extravasates through the vascular wall to the interstitial space, then is transported to LNs via 

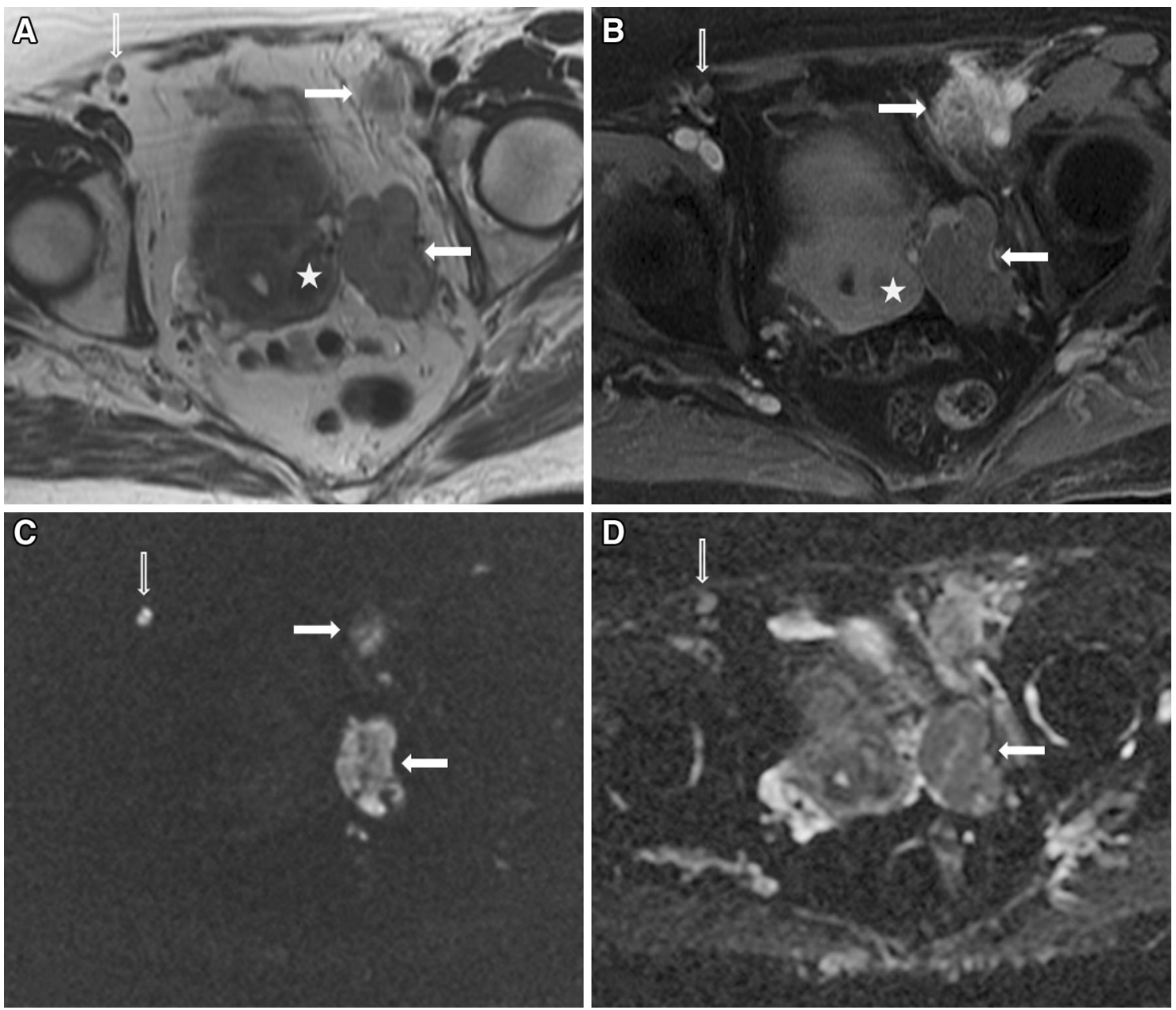

Fig. 5 A 88-year-old female patient with metastatic adenocarcinoma from unknown primary tumor. a Axial T2-weighted MR image revealed enlarged metastatic lymph nodes (arrows) in the left internal and external iliac chain (the largest one was $3 \times 4.6 \mathrm{~cm}$ ) as well as a subcentimeter reactive lymph node (hallow arrow) was detected in the right deep inguinal area. Also noted was a fibroid (asterisk) in the posterior wall of uterus. b Enlarged left iliac lymph nodes (arrows)

lymphatic vessels and internalized by macrophages. The normal parts of nodes with uptake of USPIO in macrophages show a signal drop on the $\mathrm{T} 2 *$-weighted sequence due to the effect of iron oxide; on the contrary, the tumor deposit parts of nodes keep relatively high signals for lack of normal macrophages. This signal contrast forms the diagnostic basis of USPIO. So far, USPIO has been the most sensitive and specific non-invasive imaging modality in LN detection. Its sensitivity, specificity, accuracy, PPV, and NPV on a patient-by-patient basis reached 90, 80-100, 87-95.7, 67-97.5, and 93-100\%, respectively [75, 76••, 77]. With a high-resolution $\mathrm{T} 2 *$-weighted sequence, this contrast may further improve the detection ability on micrometastatic deposits in normal-size nodes [78]; see Fig. 6. Harisinghani et al. reported relatively satisfying diagnostic results on nodes with a short-axis diameter less

manifested heterogeneous enhancement on enhanced T1-weighted MR image. c All bilateral pelvic lymph nodes displayed high signal while the fibroid did not show any abnormal signal on diffusion image with a $b$ value of $600 \mathrm{~mm}^{2} / \mathrm{s}$. d The ADC value of metastatic node (arrow) adjacent to left internal iliac vessels was lower than the value of benign node (hallow arrow) located in right inguinal area on ADC map, 0.75 versus $0.94 \times 10^{-3} \mathrm{~mm}^{2} / \mathrm{s}$

than $5 \mathrm{~mm}$ using ferumoxtran-10. The sensitivity, specificity, accuracy, positive predictive value, and negative predictive value on a node-by-node basis were 41.1, 98.1, 90.4, 77.7 and $91.3 \%$, respectively [76]. Unfortunately, without approval by the FDA, ferumoxtran-10 is still unavailable in clinics. Moreover, being time consuming in both examination and review is an underlying obstacle to gaining wide acceptance. Thoeny et al. reliably decreased the reading time of USPIO from 80 to 13 min utilizing a combined approach called USPIO-DW-MRI in patients with prostate cancer [75].

\section{PET/CT (MRI)}

PET is a functional nuclear imaging method for detecting pairs of gamma rays emitted indirectly by special 
Fig. 6 Lymphotropic nanoparticle enhanced MRI (Ferumoxtran-10) allows for characterization of small size (diameter $<10 \mathrm{~mm}$ ) lymph nodes in pelvis. a Precontrast $\mathrm{T} 2 *$ image showed there were two small benign external iliac lymph nodes (arrows), with a big hilar (asterisk) in the larger one. b Both nodes showed homogeneous decrease of the signal. c Another round shape lymph node presented slightly high signal on precontrast $\mathrm{T} 2 *$ image. $\mathbf{d}$ The signal of a involved part of the node (asterisk) decreased on postcontrast image, while the uninvolved part (hallow asterisk) kept the sightly high signal
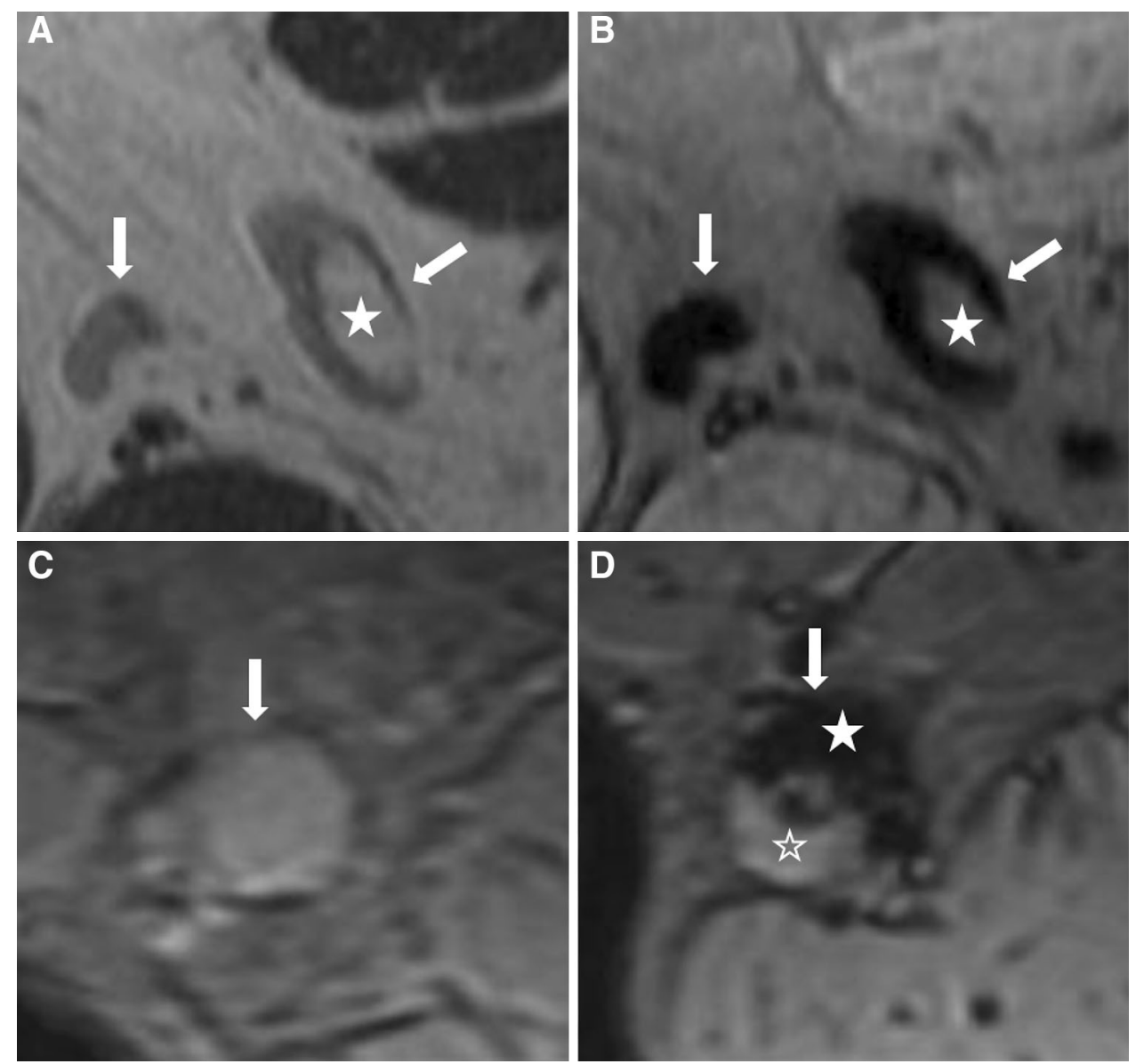

radioactive tracers. [18F]-fluoro-2-deoxy-D-glucose (18FFDG) is the most popular tracer at present, which can reflect the increased glucose metabolism in most types of malignant tumor cells. However, its application in prostate cancer does not proceed smoothly for three reasons: one is that most prostate cancers are not very $18 \mathrm{~F}-\mathrm{FDG}$ avid; second is the overlap of FDG uptake noted among normal, hyperplastic, and malignant tissues, especially when lesions are small or diffuse or mixed with noncancerous cells; third, the excretion of FDG through the bladder can be confused with the spread in prostate cancer [79]. As an alternative to 18F-FDG, [11C]-choline shows good outcomes in staging prostate cancer on PET. The increase in cell proliferation and $\mathrm{CHK} \alpha$ expression in prostate cancer cells induces increased uptake of choline and its by-products [80], consequently showing a signal increase on PET. Fusion PET with CT or MRI is helpful in improving the spatial resolution and consequently strengthening the detection ability on nodes with diameters less than $1 \mathrm{~cm}$ or located adjacent to the primary tumor [81]. In ovarian cancer, the accuracy, sensitivity, specificity, PPV, and NPV of PET/CT could reach 83.3, 98.2, 95.6, 90.9, and 96.5\%, respectively [82]; in cervical cancer, the corresponding values were $99.3,72,99.7,81$, and $99.5 \%$, respectively
[83••]; in prostate cancer, the corresponding values of $11 \mathrm{C}$ choline PET/CT were 60.0, 97.6, 87.7, 90.0, and 87.2\%, respectively [84]. In addition, the overlapping uptake between malignant and benign nodes also makes the interpretation more challenging; see Fig. 7. Familiarity with the nodal drainage pathways may help to make a more appropriate judgment. For instance, abnormal uptake in the mid-external iliac chains and more proximally should lead to high suspicion of metastasis in prostate cancer. In contrast, low-level $11 \mathrm{C}$-choline nodal activity is frequently seen in benign inguinal LNs [85•].

\section{SPECT/CT (MRI) LSG}

SPECT/CT (MRI) LSG is another hybrid nuclear method combining conventional LSG with 3D CT or MRI images. The most common radiotracer is $99 \mathrm{mTc}$ nanocolloid. This modality is usually adopted in preoperative SLN mapping owing to its better anatomic location [86]. SPECT/CT LSG presented a significantly higher detection rate of a singular SLN than of planar LSG, 92.2 versus $84.3 \%$ in cervical cancer [87] and 98 versus $91 \%$ in prostate cancer [88], especially when SLNs are located near the injection area, such as the parametrial area in cervical cancer. 

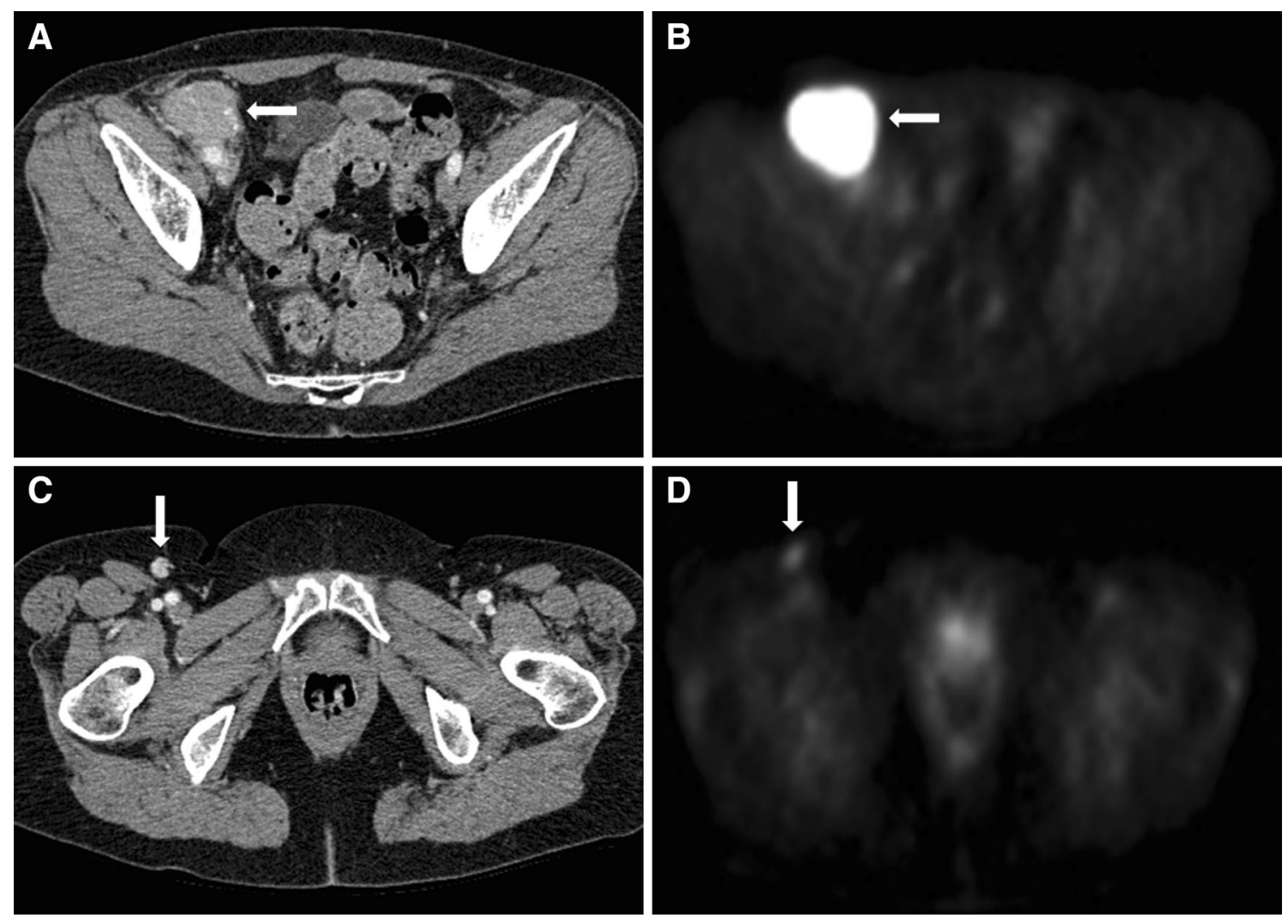

Fig. 7 A 62-year-old female patient with pelvic metastases from cervical cancer. a Axial enhanced CT image demonstrated a $3.4 \times 4.0 \mathrm{~cm}$ metastatic lymph node (arrow) adjacent to right external iliac vessels, with moderate homogeneous enhancement. b The enlarged external iliac lymph node (arrow) showed significant

high 18-FDG uptake on PET image. c Another right inguinal lymph node (arrow) with a short diameter of $9 \mathrm{~mm}$ was noted on the lower axial CT image in the same patient. d This inguinal lymph node (arrow) also showed moderate FDG uptake on PET image but was confirmed as reactive node

\section{ICT (MRI) LG}

ICT (MRI) LG is a newly emerging technology on LN mapping and currently has only been used in preclinical and limited clinical trials. In this modality, small-sized particulate contrast agents, subcutaneously injected, travel into the lymphatic vessels because of the increased permeability of the fenestrated endothelial lining of the distal lymphatic capillaries and then accumulate in the afferent LNs [89]. Common contrast agents include iopamidol in CT and gadoterate meglumine, gadodiamide, gadofluoramide, and gadofluorine 8 in MRI. The peritumoral area is commonly chosen as the injection site, and the optimal scan time is about $30 \mathrm{~min}$ to $2 \mathrm{~h}$ after injection. These technologies provide the visualization of the direct connection between the primary SLN and its afferent lymphatic vessels as well as high-resolution anatomic images of lymphatic basin $[90,91 \cdot]$. In a study of cervical cancer, IMRLG demonstrated a significantly higher accuracy in the detection of SLN than blue dye lymphography, 85 versus $61 \%$, with an accuracy, sensitivity, specificity, PPD, and NPD of 92.9, 80, 95.7, 100, and $95.7 \%$, respectively.

However, this techology is not suitable for use in pelvic LNs because it is difficult to find a proper injection site for deep pelvic tumors [90]. Besides, the large volume of contrast agent administered subcutaneously may be an obstacle to its application [91].

\section{New Modalities}

Besides these routine imaging methods discussed above, some new emerging technologies, such as photoacoustic imaging and targeting nanotechnology, have contributed to detecting lymphatic metastasis. Photoacoustic imaging is a hybrid biomedical imaging modality based on the photoacoustic effect. In this technology, non-ionizing laser pulses are delivered into biological tissues. Some of the delivered energy leads to transient thermoelastic expansion and a pressure wave (i.e., photoacoustic signal) that can be

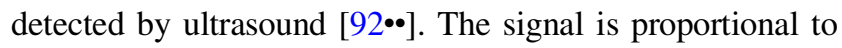
the local energy deposition and reveals physiologically specific optical absorption contrast, based on which 2D or 3D images of the targeted areas can be formed. The tracers 
used in photoacoustic imaging for SLN mapping include indocyanine green, methylene blue, near-infrared dye, and gold nanoparticles. Song et al. demonstrated that a new class of lymph node tracers, Au nanocages (near-infrared gold nanocages), allows identifying SLNs as deep as $33 \mathrm{~mm}$ below the skin surface with good contrast, and these tracers can be easily bioconjugated with antibodies for targeting specific receptors [93]. Although this modality has shown good potential in noninvasive imaging for SLNs in breast cancer and melanoma patients, new contrast agents with higher penetrability and sensitivity need to be developed if extended to deeper abdominal and pelvic regions. Targeting nanotechnology is another potential modality in lymph node mapping with conjugation of biorecognition polymers to nanoparticles, which also shows good prospects in tumor therapy. Hyaluronan, quantum dots, and iron oxide nanoparticles are common nanoconjugates. Depending on the nanoconjugate of hyaluronan with a fluorescent tag, Cai et al. clearly localized nodes with hyaluronan surrounding an implanted breast tumor and also decreased breast cancer progression by a hyaluronandoxorubicin nanoconjugate in vivo mouse study [94].

\section{Conclusion}

In this review, we summarized the general and specific pelvic LN drainage pathways as well as SLN landing sites in each individual pelvic tumor. Moreover, the basic principles and characteristics of conventional and emerging imaging modalities for the assessment of pelvic LNs are also elaborated in this article. Combining the lymphatic drainage and imaging information will help radiologists and surgeons make better decisions about the diagnosis and treatments in pelvic diseases. Moreover, the technical advances in functional MRI, lymphotropic MR contrast, hybrid nuclear methods, and other new imaging modalities might eliminate the limitations to the detection of micrometastases within normal-size LNs in the future.

\section{Compliance with Ethics Guidelines}

Conflict of Interest Dr. Yun Mao, Dr. Sandeep Hedgire, Dr. Duangkamon Prapruttam, and Dr. Mukesh Harisinghani each declare no potential conflicts of interest.

Human and Animal Rights and Informed Consent This article does not contain any studies with human or animal subjects performed by any of the authors.

\section{References}

Papers of particular interest, published recently, have been highlighted as
- Of importance

-• Of major importance

1. - Harisinghani MG. Atlas of lymph node anatomy. New York: Springer; 2012. This book carefully described various pelvic lymphatic drainage pathways with corresponding illustrations.

2. de Jong IJ, Pruim J, Elsinga PH, Vaalburg W, Mensink HJ. Preoperative staging of pelvic lymph nodes in prostate cancer by 11C-choline PET. J Nucl Med. 2003;44:331-5.

3. Paulson DF. Carcinoma of the prostate: the therapeutic dilemma. Annu Rev Med. 1984;35:341-72.

4. - Mattei A, Fuechsel FG, Bhatta DN, Warncke SH, Thalmann GN, Krause T, et al. The template of the primary lymphatic landing sites of the prostate should be revisited: results of a multimodality mapping study. Eur Urol. 2008;53:118-25. This article mapped the primary lymphatic landing sites of prostate cancer by a multimodality technique and discussed opinions about improvement of traditional pelvic lymphadenectomy according to the mapping.

5. Weckermann D, Dorn R, Trefz M, Wagner T, Wawroschek F, Harzmann R. Sentinel lymph node dissection for prostate cancer: experience with more than 1,000 patients. J Urol. 2007;177:916-20.

6. Briganti A, Suardi N, Capogrosso P, Passoni N, Freschi M, di Trapani E, et al. Lymphatic spread of nodal metastases in highrisk prostate cancer: the ascending pathway from the pelvis to the retroperitoneum. Prostate. 2012;72:186-92.

7. Joniau S, Van den Bergh L, Lerut E, Deroose CM, Haustermans $\mathrm{K}$, Oyen R, et al. Mapping of pelvic lymph node metastases in prostate cancer. Eur Urol. 2013;63:450-8.

8. Barranger E, Cortez A, Uzan S, Callard P, Darai E. Value of intraoperative imprint cytology of sentinel nodes in patients with cervical cancer. Gynecol Oncol. 2004;94:175-80.

9. Kamura T, Tsukamoto N, Tsuruchi N, Saito T, Matsuyama T, Akazawa K, et al. Multivariate analysis of the histopathologic prognostic factors of cervical cancer in patients undergoing radical hysterectomy. Cancer. 1992;69:181-6.

10. Lanciano RM, Corn BW. The role of surgical staging for cervical cancer. Semin Radiat Oncol. 1994;4:46-51.

11. Twombly GH. The lymphatics of the female genital organs. Ann Surg. 1965;162:1045-68.

12. - Benedetti-Panici P, Maneschi F, Scambia G, Greggi S, Cutillo G, D'Andrea G, et al. Lymphatic spread of cervical cancer: an anatomical and pathological study based on 225 radical hysterectomies with systematic pelvic and aortic lymphadenectomy. Gynecol Oncol. 1996;62:19-24. The article provided many useful data on the lymph node distribution of cervical cancer for tailoring radical hysterectomy and lymphadenectomy.

13. Marnitz S, Kohler C, Bongardt S, Braig U, Hertel H, Schneider A. Topographic distribution of sentinel lymph nodes in patients with cervical cancer. Gynecol Oncol. 2006;103:35-44.

14. Rob L, Strnad P, Robova H, Charvat M, Pluta M, Schlegerova $\mathrm{D}$, et al. Study of lymphatic mapping and sentinel node identification in early stage cervical cancer. Gynecol Oncol. 2005;98:281-8.

15. Benedetti-Panici P, Maneschi F, D'Andrea G, Cutillo G, Rabitti $\mathrm{C}$, Congiu M, et al. Early cervical carcinoma: the natural history of lymph node involvement redefined on the basis of thorough parametrectomy and giant section study. Cancer. 2000;88: 2267-74.

16. Sakuragi N, Satoh C, Takeda N, Hareyama H, Takeda M, Yamamoto R, et al. Incidence and distribution pattern of pelvic and paraaortic lymph node metastasis in patients with stages IB, IIA, and IIB cervical carcinoma treated with radical hysterectomy. Cancer. 1999;85:1547-54. 
17. Mills RD, Turner WH, Fleischmann A, Markwalder R, Thalmann GN, Studer UE. Pelvic lymph node metastases from bladder cancer: outcome in 83 patients after radical cystectomy and pelvic lymphadenectomy. J Urol. 2001;166:19-23.

18. Frank I, Cheville JC, Blute ML, Lohse CM, Nehra A, Weaver $\mathrm{AL}$, et al. Transitional cell carcinoma of the urinary bladder with regional lymph node involvement treated by cystectomy: clinicopathologic features associated with outcome. Cancer. 2003;97: 2425-31.

19. Vogelzang NJ, Scardino PT, Shipley WU, Debruyne FMJ, Linehan WM, editors. Comprehensive textbook of genitourinary oncology. 3rd ed. Philadelphia, Pa: Lippincott Williams \& Wilkins; 2006.

20. Abol-Enein H, El-Baz M, Abd EM, Abdel-Latif M, Ghoneim MA. Lymph node involvement in patients with bladder cancer treated with radical cystectomy: a patho-anatomical study-a single center experience. J Urol. 2004;172:1818-21.

21. • Pano B, Sebastia C, Bunesch L, Mestres J, Salvador R, Macias NG, et al. Pathways of lymphatic spread in male urogenital pelvic malignancies. Radiographics. 2011;31:135-60. Nice review of lymphatic spread in various male urogenital pelvic tumors.

22. Vieweg J, Gschwend JE, Herr HW, Fair WR. Pelvic lymph node dissection can be curative in patients with node positive bladder cancer. J Urol. 1999;161:449-54.

23. Leissner J, Ghoneim MA, Abol-Enein H, Thuroff JW, Franzaring L, Fisch M, et al. Extended radical lymphadenectomy in patients with urothelial bladder cancer: results of a prospective multicenter study. J Urol. 2004;171:139-44.

24. Morrow CP, Di Saia PJ, Townsend DE. Current management of endometrial carcinoma. Obstet Gynecol. 1973;42:399-406.

25. Morrow CP, Bundy BN, Kurman RJ, Creasman WT, Heller P, Homesley HD, et al. Relationship between surgical-pathological risk factors and outcome in clinical stage I and II carcinoma of the endometrium: a gynecologic oncology group study. Gynecol Oncol. 1991;40:55-65.

26. Yokoyama Y, Maruyama H, Sato S, Saito Y. Indispensability of pelvic and paraaortic lymphadenectomy in endometrial cancers. Gynecol Oncol. 1997;64:411-7.

27. - Mariani A, Webb MJ, Keeney GL, Podratz KC. Routes of lymphatic spread: a study of 112 consecutive patients with endometrial cancer. Gynecol Oncol. 2001;81:100-4. This article assessed different patterns of lymphatic spread to pelvic and para-aortic lymph nodes in endometrial cancer.

28. Lecuru F, Neji K, Robin F, Darles C, de Bievre P, Taurelle R. Lymphatic drainage of the uterus. Preliminary results of an experimental study. J Gynecol Obstet Biol Reprod (Paris). 1997;26:418-23.

29. Kleppe M, Amkreutz LC, Van Gorp T, Slangen BF, Kruse AJ, Kruitwagen RF. Lymph-node metastasis in stage I and II sex cord stromal and malignant germ cell tumours of the ovary: a systematic review. Gynecol Oncol. 2014;133:124-7.

30. Kleppe M, Wang T, Van Gorp T, Slangen BF, Kruse AJ, Kruitwagen RF. Lymph node metastasis in stages I and II ovarian cancer: a review. Gynecol Oncol. 2011;123:610-4.

31. • Burghardt E, Girardi F, Lahousen M, Tamussino K, Stettner H. Patterns of pelvic and paraaortic lymph node involvement in ovarian cancer. Gynecol Oncol. 1991;40:103-6. This article discussed the lymph metastatic patterns of ovarian cancer as well as the correlations between the clinical stage or survival and features of positive lymph nodes.

32. Yang XJ, Zheng FY, Xu YS, Ou RY. Ovarian cancer initially presenting with isolated ipsilateral superficial inguinal lymph node metastasis: a case study and review of the literature. J Ovarian Res. 2014;7:20.

33. Pereira A, Magrina JF, Rey V, Cortes M, Magtibay PM. Pelvic and aortic lymph node metastasis in epithelial ovarian cancer. Gynecol Oncol. 2007;105:604-8.
34. Cass I, Li AJ, Runowicz CD, Fields AL, Goldberg GL, Leuchter RS, et al. Pattern of lymph node metastases in clinically unilateral stage I invasive epithelial ovarian carcinomas. Gynecol Oncol. 2001;80:56-61.

35. Frumovitz M, Gayed IW, Jhingran A, Euscher ED, Coleman RL, Ramirez PT, et al. Lymphatic mapping and sentinel lymph node detection in women with vaginal cancer. Gynecol Oncol. 2008;108:478-81.

36. Gall FP. Hermanek P [Expanded lymph node dissection in stomach and colorectal cancer-uses and risks]. Chirurg. 1988;59: 202-10.

37. Joosten JJ, Strobbe LJ, Wauters CA, Pruszczynski M, Wobbes T, Ruers TJ. Intraoperative lymphatic mapping and the sentinel node concept in colorectal carcinoma. Br J Surg. 1999;86:482-6.

38. Ueno H, Yamauchi C, Hase K, Ichikura T, Mochizuki H. Clinicopathological study of intrapelvic cancer spread to the iliac area in lower rectal adenocarcinoma by serial sectioning. Br J Surg. 1999;86:1532-7.

39. Hojo K, Koyama Y, Moriya Y. Lymphatic spread and its prognostic value in patients with rectal cancer. Am J Surg. 1982;144:350-4.

40. Fujita S, Yamamoto S, Akasu T, Moriya Y. Lateral pelvic lymph node dissection for advanced lower rectal cancer. Br J Surg. 2003;90:1580-5.

41. - Steup WH, Moriya Y, van de Velde CJ. Patterns of lymphatic spread in rectal cancer. A topographical analysis on lymph node metastases. Eur J Cancer. 2002;38:911-8. This article assessed the correlations between lymph node metastasis and features of primary tumors in rectal cancer.

42. Williams AD, Cousins C, Soutter WP, Mubashar M, Peters AM, Dina $\mathrm{R}$, et al. Detection of pelvic lymph node metastases in gynecologic malignancy: a comparison of CT, MR imaging, and positron emission tomography. AJR Am J Roentgenol. 2001;177: 343-8.

43. Torabi M, Aquino SL, Harisinghani MG. Current concepts in lymph node imaging. J Nucl Med. 2004;45:1509-18.

44. McMahon CJ, Rofsky NM, Pedrosa I. Lymphatic metastases from pelvic tumors: anatomic classification, characterization, and staging. Radiology. 2010;254:31-46.

45. Hovels AM, Heesakkers RA, Adang EM, Jager GJ, Strum S, Hoogeveen YL, et al. The diagnostic accuracy of CT and MRI in the staging of pelvic lymph nodes in patients with prostate cancer: a meta-analysis. Clin Radiol. 2008;63:387-95.

46. Tempany CM, Zou KH, Silverman SG, Brown DL, Kurtz AB, McNeil BJ. Staging of advanced ovarian cancer: comparison of imaging modalities-report from the Radiological Diagnostic Oncology Group. Radiology. 2000;215:761-7.

47. Heesakkers RA, Hovels AM, Jager GJ, van den Bosch HC, Witjes JA, Raat HP, et al. MRI with a lymph-node-specific contrast agent as an alternative to CT scan and lymph-node dissection in patients with prostate cancer: a prospective multicohort study. Lancet Oncol. 2008;9:850-6.

48. American joint committee on cancer. AJCC cancer staging manual. 6th ed. New York: Springer-Verlag; 2002.

49. Fregnani JH, Latorre MR, Novik PR, Lopes A, Soares FA. Assessment of pelvic lymph node micrometastatic disease in stages IB and IIA of carcinoma of the uterine cervix. Int $\mathrm{J}$ Gynecol Cancer. 2006;16:1188-94.

50. Horn LC, Hentschel B, Fischer U, Peter D, Bilek K. Detection of micrometastases in pelvic lymph nodes in patients with carcinoma of the cervix uteri using step sectioning: frequency, topographic distribution and prognostic impact. Gynecol Oncol. 2008;111:276-81.

51. Heesakkers RA, Hovels AM, Jager GJ, van den Bosch HC, Witjes JA, Raat HP, et al. MRI with a lymph-node-specific contrast agent as an alternative to CT scan and lymph-node 
dissection in patients with prostate cancer: a prospective multicohort study. Lancet Oncol. 2008;9:850-6.

52. Yang WT, Lam WW, Yu MY, Cheung TH, Metreweli C. Comparison of dynamic helical $\mathrm{CT}$ and dynamic MR imaging in the evaluation of pelvic lymph nodes in cervical carcinoma. AJR Am J Roentgenol. 2000;175:759-66.

53. Burkill GJ, Allen SD, A'Hern RP, Gore ME, King DM. Significance of tumour calcification in ovarian carcinoma. Br J Radiol. 2009;82:640-4.

54. Kim AY, Kim HJ, Ha HK. Gastric cancer by multidetector row CT: preoperative staging. Abdom Imaging. 2005;30:465-72.

55. Ricke J, Sehouli J, Hach C, Hanninen EL, Lichtenegger W, Felix R. Prospective evaluation of contrast-enhanced MRI in the depiction of peritoneal spread in primary or recurrent ovarian cancer. Eur Radiol. 2003;13:943-9.

56. Choi HJ, Kim SH, Seo SS, Kang S, Lee S, Kim JY, et al. MRI for pretreatment lymph node staging in uterine cervical cancer. AJR Am J Roentgenol. 2006;187:W538-43.

57. Kim NK, Kim MJ, Yun SH, Sohn SK, Min JS. Comparative study of transrectal ultrasonography, pelvic computerized tomography, and magnetic resonance imaging in preoperative staging of rectal cancer. Dis Colon Rectum. 1999;42:770-5.

58. Lin G, Ho KC, Wang JJ, Ng KK, Wai YY, Chen YT, et al. Detection of lymph node metastasis in cervical and uterine cancers by diffusion-weighted magnetic resonance imaging at 3T. J Magn Reson Imaging. 2008;28:128-35.

59. Dooms GC, Hricak H, Moseley ME, Bottles K, Fisher M, Higgins CB. Characterization of lymphadenopathy by magnetic resonance relaxation times: preliminary results. Radiology. 1985;155:691-7.

60. Chen YB, Liao J, Xie R, Chen GL, Chen G. Discrimination of metastatic from hyperplastic pelvic lymph nodes in patients with cervical cancer by diffusion-weighted magnetic resonance imaging. Abdom Imaging. 2011;36:102-9.

61. Kim SH, Kim SC, Choi BI, Han MC. Uterine cervical carcinoma: evaluation of pelvic lymph node metastasis with MR imaging. Radiology. 1994;190:807-11.

62. Fischbein NJ, Noworolski SM, Henry RG, Kaplan MJ, Dillon WP, Nelson SJ. Assessment of metastatic cervical adenopathy using dynamic contrast-enhanced MR imaging. AJNR Am J Neuroradiol. 2003;3:301-11.

63. Wang J, Takashima S, Takayama F, Kawakami S, Saito A, Matsushita T, et al. Head and neck lesions: characterization with diffusionweighted echo-planar MR imaging. Radiology. 2001;220:621-30.

64. Eiber M, Beer AJ, Holzapfel K, Tauber R, Ganter C, Weirich G, et al. Preliminary results for characterization of pelvic lymph nodes in patients with prostate cancer by diffusion-weighted MRimaging. Invest Radiol. 2010;45:15-23.

65. Ono K, Ochiai R, Yoshida T, Kitagawa M, Omagari J, Kobayashi $\mathrm{H}$, et al. Comparison of diffusion-weighted MRI and 2-[fluorine18]-fluoro-2-deoxy-D-glucose positron emission tomography (FDG-PET) for detecting primary colorectal cancer and regional lymph node metastases. J Magn Reson Imaging. 2009;29:336-40.

66. Heck MM, Souvatzoglou M, Retz M, Nawroth R, Kubler H, Maurer T, et al. Prospective comparison of computed tomography, diffusion-weighted magnetic resonance imaging and [11C]choline positron emission tomography/computed tomography for preoperative lymph node staging in prostate cancer patients. Eur J Nucl Med Mol Imaging. 2014;41:694-701.

67. •• Kim JK, Kim KA, Park BW, Kim N, Cho KS. Feasibility of diffusion-weighted imaging in the differentiation of metastatic from nonmetastatic lymph nodes: early experience. J Magn Reson Imaging. 2008;28:714-9. This study demonstrated the significant difference in $A D C$ value between metastatic and nonmetastatic lymph nodes and confirmed the value of DWI on lymph node assessment in cervical cancer.
68. Kitajima K, Yamasaki E, Kaji Y, Murakami K, Sugimura K. Comparison of DWI and PET/CT in evaluation of lymph node metastasis in uterine cancer. World J Radiol. 2012;4:207-14.

69. Provenzale JM, Mukundan S, Barboriak DP. Diffusion-weighted and perfusion MR imaging for brain tumor characterization and assessment of treatment response. Radiology. 2006;239:632-49.

70. Sumi M, Van Cauteren M, Nakamura T. MR microimaging of benign and malignant nodes in the neck. AJR Am J Roentgenol. 2006;186:749-57.

71. Perrone A, Guerrisi P, Izzo L, D’Angeli I, Sassi S, Mele LL, et al. Diffusion-weighted MRI in cervical lymph nodes: differentiation between benign and malignant lesions. Eur J Radiol. 2011;77:281-6.

72. Bammer R, Holdsworth SJ, Veldhuis WB, Skare ST. New methods in diffusion-weighted and diffusion tensor imaging. Magn Reson Imaging Clin N Am. 2009;17:175-204.

73. Takahara $T$, Imai $Y$, Yamashita $T$, Yasuda $S$, Nasu $S$, Van Cauteren M. Diffusion weighted whole body imaging with background body signal suppression (DWIBS): technical improvement using free breathing, STIR and high resolution 3D display. Radiat Med. 2004;22:275-82.

74. Roy C, Bierry G, Matau A, Bazille G, Pasquali R. Value of diffusion-weighted imaging to detect small malignant pelvic lymph nodes at 3 T. Eur Radiol. 2010;20:1803-11.

75. Thoeny HC, Triantafyllou M, Birkhaeuser FD, Froehlich JM, Tshering DW, Binser T, et al. Combined ultrasmall superparamagnetic particles of iron oxide-enhanced and diffusion-weighted magnetic resonance imaging reliably detect pelvic lymph node metastases in normal-sized nodes of bladder and prostate cancer patients. Eur Urol. 2009;55:761-9.

76. •• Harisinghani MG, Barentsz J, Hahn PF, Deserno WM, Tabatabaei $\mathrm{S}$, van de $\mathrm{Kaa} \mathrm{CH}$, et al. Noninvasive detection of clinically occult lymph-node metastases in prostate cancer. $\mathrm{N}$ Engl $\mathrm{J}$ Med. 2003;348:2491-9. This study demonstrated the advantage of USPIO for the detection of normal-size metastatic lymph nodes in prostate cancer.

77. Heesakkers RA, Hovels AM, Jager GJ, van den Bosch HC, Witjes JA, Raat HP, et al. MRI with a lymph-node-specific contrast agent as an alternative to CT scan and lymph-node dissection in patients with prostate cancer: a prospective multicohort study. Lancet Oncol. 2008;9:850-6.

78. Anzai Y, Piccoli CW, Outwater EK, Stanford W, Bluemke DA, Nurenberg $\mathrm{P}$, et al. Evaluation of neck and body metastases to nodes with ferumoxtran 10-enhanced MR imaging: phase III safety and efficacy study. Radiology. 2003;228:777-88.

79. Salminen E, Hogg A, Binns D, Frydenberg M, Hicks R. Investigations with FDG-PET scanning in prostate cancer show limited value for clinical practice. Acta Oncol. 2002;41:425-9.

80. Kotzerke J, Prang J, Neumaier B, Volkmer B, Guhlmann A, Kleinschmidt K, et al. Experience with carbon-11 choline positron emission tomography in prostate carcinoma. Eur J Nucl Med. 2000;27:1415-9.

81. Lardinois D, Weder W, Hany TF, Kamel EM, Korom S, Seifert B, et al. Staging of non-small-cell lung cancer with integrated positron-emission tomography and computed tomography. N Engl J Med. 2003;348:2500-7.

82. Signorelli M, Guerra L, Pirovano C, Crivellaro C, Fruscio R, Buda A, et al. Detection of nodal metastases by 18F-FDG PET/ CT in apparent early stage ovarian cancer: a prospective study. Gynecol Oncol. 2013;131:395-9.

83. •• Sironi S, Buda A, Picchio M, Perego P, Moreni R, Pellegrino A, et al. Lymph node metastasis in patients with clinical earlystage cervical cancer: detection with integrated FDG PET/CT. Radiology. 2006;238:272-9. This study demonstrated PET/CT could accurately evaluate metastatic nodes with short-axis diameter greater than $0.5 \mathrm{~cm}$ in early stage cervical cancer. 
84. Schiavina R, Scattoni V, Castellucci P, Picchio M, Corti B, Briganti A, et al. 11C-choline positron emission tomography/ computerized tomography for preoperative lymph-node staging in intermediate-risk and high-risk prostate cancer: comparison with clinical staging nomograms. Eur Urol. 2008;54:392-401.

85. - Murphy RC, Kawashima A, Peller PJ. The utility of 11C-choline PET/CT for imaging prostate cancer: a pictorial guide. AJR Am J Roentgenol. 2011;196:1390-8. The writers provided a useful guide of the lymph node evaluation on 11C-choline PET/ $C T$ in prostate cancer.

86. Even-Sapir E, Lerman H, Lievshitz G, Khafif A, Fliss DM, Schwartz A, et al. Lymphoscintigraphy for sentinel node mapping using a hybrid SPECT/CT system. J Nucl Med. 2003;44:1413-20.

87. Klapdor R, Mucke J, Schneider M, Langer F, Gratz KF, Hillemanns $\mathrm{P}$, et al. Value and advantages of preoperative sentinel lymph node imaging with SPECT/CT in cervical cancer. Int $\mathrm{J}$ Gynecol Cancer. 2014;24:295-302.

88. Vermeeren L, Valdes OR, Meinhardt W, Bex A, van der Poel HG, Vogel WV, et al. Value of SPECT/CT for detection and anatomic localization of sentinel lymph nodes before laparoscopic sentinel node lymphadenectomy in prostate carcinoma. J Nucl Med. 2009;50:865-70.

89. Moghimi SM, Bonnemain B. Subcutaneous and intravenous delivery of diagnostic agents to the lymphatic system: applications in lymphoscintigraphy and indirect lymphography. Adv Drug Deliv Rev. 1999;37:295-312.

90. Hong Y, Xiang L, Hu Y, Zhou Z, Yu H, Zhu B. Interstitial magnetic resonance lymphography is an effective diagnostic tool for the detection of lymph node metastases in patients with cervical cancer. BMC Cancer. 2012;12:360.

91. - Staatz G, Nolte-Ernsting CC, Adam GB, Grosskortenhaus S, Misselwitz B, Bucker A, et al. Interstitial T1-weighted MR lymphography: lipophilic perfluorinated gadolinium chelates in pigs. Radiology. 2001;220:129-34. The study demonstrated the feasibility of interstitial MR lymphography and assessed the strengths and weaknesses.

92. • Cohen S M, Fishinghawk B G, Cohen M S. Translational imaging of lymphatics in cancer. Adv Drug Deliv Rev. 2011;63:956-62. This review explored the modern uses of early modalities and also depicted some new modalities currently in development and their potential uses for the future.

93. Song KH, Kim C, Cobley CM, et al. Near-infrared gold nanocages as a new class of tracers for photoacoustic sentinel lymph node mapping on a rat model. Nano Lett. 2008;9:183-8.

94. Cai S, Thati S, Bagby TR, et al. Localized doxorubicin chemotherapy with a biopolymeric nanocarrier improves survival and reduces toxicity in xenografts of human breast cancer. J Controlled. 2010;146:212-8. 